\title{
NOVOS MODELOS DE GESTÃO DO TRABALHO NO SETOR PÚBLICO DE SAÚDE E O TRABALHO DO AGENTE COMUNITÁRIO DE SAÚDE
}

\author{
NEW WORK MANAGEMENT MODELS IN THE PUBLIC HEALTH SECTOR AND THE WORK OF \\ THE COMMUNITY HEALTH AGENT
}

NUEVOS MODELOS DE GESTIÓN DEL TRABAJO EN EL SECTOR PÚBLICO DE SALUD Y EL TRABAJO

DEL AGENTE COMUNITARIO DE SALUD

\author{
Carla Cabral Gomes Carneiro ${ }^{1}$ \\ Maria Inês Carsalade Martins ${ }^{2}$
}

Resumo Este artigo discute a parceria do Estado com organizações sociais para a gestão do trabalho em saúde no setor público, com ênfase no trabalho do agente comunitário de saúde. Trata-se de um estudo de caso realizado no município do Rio de Janeiro numa conjuntura de expansão da cobertura da Estratégia Saúde da Família. O tema é analisado num contexto mais amplo de reforma do Estado brasileiro, partindo-se do entendimento de que o movimento reformista da administração pública, conhecido como gerencialismo, guarda estreita relação nas suas ações e valores com a reestruturação produtiva iniciada nos anos 1970. Os resultados mostram que o modelo de gestão do trabalho implantado opera sob a lógica da produtividade, influenciando o modelo de atenção à saúde prestado à população e a organização do trabalho do agente comunitário de saúde. A análise também destaca a temporalidade e a externalidade dos vínculos de trabalho como fatores que podem comprometer os avanços da democratização, equidade e cidadania no campo da saúde e do trabalho conquistados na Constituição brasileira de 1988.

Palavras-chave novos modelos de gestão do trabalho em saúde; reforma do Estado; contratualização; trabalho em saúde; agente comunitário de saúde.

\begin{abstract}
This article discusses the partnership between the State and social organizations for the management of health work in the public sector, with emphasis on the work of the community health agent. This is a case study carried out in the municipality of Rio de Janeiro, Brazil, in an environment of expansions in the coverage of the Family Health Strategy. The topic is analyzed in a context of a broader reform of the Brazilian State, starting from the understanding that the public administration reform movement, known as managerialism, is closely related in their actions and values with the productive restructuring that got underway in the 1970s. The results show that the work management model that was deployed operates under the logic of productivity, influencing the model of the health care provided to the population and the organization of the work done by the community health agent. The analysis also highlights the temporality and externality of the work ties as factors that can compromise the progress of democratization, equity, and citizenship in the field of health and work ensured by the Brazilian Constitution of 1988.

Keywords new management models in health work; reform of the State; contracting; work in health; community health agent.
\end{abstract}




\section{Introdução}

A Constituição brasileira de 1988, aprovada no momento da redemocratização do país, representa uma conquista política e um avanço no sentido da democratização e da cidadania. Nela institui-se, entre outras conquistas sociais, a universalização da saúde por meio do Sistema Único de Saúde (SUS) e o Regime Jurídico Único (RJU). A primeira tem como proposta a mudança no modelo de atenção à saúde no Brasil, reconhecendo a saúde como um direito de todos e um dever do Estado. O segundo institui um novo arcabouço jurídico-institucional para o serviço público, normatizando as contratações e criando um regime próprio para o servidor público.

O desafio de implantar essas mudanças estruturais no modelo de atenção à saúde e no modelo de gestão do trabalho no setor público no Brasil ocorre em uma conjuntura adversa, representada pela reforma do Estado brasileiro que vem se implantando nas duas últimas décadas. As propostas reformistas estão relacionadas às transformações do papel do Estado e de seu funcionamento e são referenciadas pela crise estrutural do capital e pela reestruturação produtiva iniciada na década de 1970.

A crise estrutural do capital suscitou transformações no modelo keynesiano-fordista de desenvolvimento, impulsionando uma nova ordem econômica marcada pela reestruturação produtiva, internacionalização do mercado e revolução tecnológica (Martins e Molinaro, 2013). De forma a recuperar a taxa de lucro e, ao mesmo tempo, responder às lutas sociais que denunciavam os métodos fordistas-tayloristas de produção (Antunes, 2011; Vieira e Chinelli, 2013), o empresariado internacional implantou novas estratégias de acumulação de capital que geraram mudanças tanto no campo da produção e do trabalho quanto na relação Estado-sociedade-mercado.

Em geral, as mudanças no processo produtivo ocorreram pelo emprego das tecnologias de base microeletrônica e de novas e mais flexíveis tecnologias de gestão que modificaram substancialmente as relações de trabalho e se impuseram como padrão de gestão predominante. A categoria central em torno da qual o conjunto de relações de trabalho se redefine é a 'flexibilização', que inicialmente pertenceu à esfera das empresas privadas, alcançando mais recentemente o setor público (Teixeira, 1999).

No que tange à relação Estado-sociedade-mercado, ganham ênfase as teses associadas aos ideais neoliberais, cujas explicações sobre as causas da crise se assentam na ideia da ineficiência do modelo burocrático de Estado, associada à alta intervenção estatal do Estado de bem-estar social nas questões econômicas e sociais. Seu discurso baseia-se na necessidade da competição pela destinação de recursos públicos ante a estagnação econômica mundial (Pereira e Linhares, 2007). 
Em linhas gerais, as principais exigências do neoliberalismo são controle do gasto público; privatização das empresas estatais; desregulamentação ou diminuição das regras que o Estado impõe ao mercado; restrição do Estado às suas funções mínimas de justiça e segurança; e redução de gastos com pessoal e flexibilização da força de trabalho, uma vez que as garantias sociais conferidas a essa última tornam-se um custo insuportável e inadmissível (Paulani, 2006).

No Brasil, os ideais reformistas emergem num momento de exacerbação das contradições econômicas e sociais silenciadas durante o período da ditadura militar e de ampliação do debate acerca da garantia dos direitos sociais para a população. Como resultado dessa tensão, a Constituição de 1988 registra algumas das demandas advindas das pressões dos movimentos sociais; no entanto, encontra, no decorrer da década de 1990, obstáculos políticos e econômicos decorrentes do pensamento neoliberal para concretizá-las (Rizzotto, 2012).

É a partir do governo de Fernando Henrique Cardoso (FHC) que o debate acerca da reforma do Estado ganha força, e propostas mais concretas de novos modelos de gestão do setor público são implantadas. O Plano Diretor da Reforma do Aparelho do Estado (PDRAE), formulado em 1995 pelo Ministério da Administração da Reforma do Estado (Brasil, 1995), sintetiza em grande medida as reformas propostas (Lima, 2010).

O PDRAE propõe uma configuração 'gerencialista' para o Estado brasileiro, na qual a administração pública assume um novo desenho institucional, desburocratizado e com maior autonomia de gestão, sendo pautada pela eficiência, orientada por resultados e baseada em contratos com órgãos internos ou com entes públicos não estatais, como as organizações sociais (OSs) (Brasil, 1995). Do ponto de vista das relações de trabalho, os ideais reformistas rompem com o RJU criando outras formas de contratação, como o emprego público e os contratos temporários, ambos mantendo o Estado como empregador, mas com contratações regidas pela Consolidação das Leis do Trabalho (CLT).

Na concepção dos formuladores do plano, assumir o modelo de administração gerencial requer que o Estado se afaste do campo da produção e da prestação de bens e serviços, e se concentre na sua função reguladora. Isso significa transferir para terceiros a execução da política de saúde e a gestão do trabalho no SUS, desresponsabilizando o Estado dos processos de seleção, gestão das relações de trabalho e qualificação da sua força de trabalho. Para os trabalhadores, significa a flexibilização das relações de trabalho estabelecidas na Constituição de 1988, levando à diminuição ou mesmo à ausência de regulação das condições, da carga horária e dos tempos de trabalho (Martins e Molinaro, 2013). 
Para a execução das atividades não exclusivas do Estado, o plano propõe as OSs, partindo do pressuposto de que esses serviços "serão mais eficientemente realizados se, mantendo o financiamento do Estado, forem realizados pelo setor público não estatal" (Brasil, 1995, p. 60). Isso implica "conceder maior autonomia de gestão a entidades descentralizadas em troca do comprometimento da organização em atingir determinados resultados" (Perdicaris, 2012, p. 3), adotar valores, ações e prerrogativas flexíveis características da reestruturação produtiva do capital (Paula, 2005) e flexibilizar as relações de trabalho no setor público estabelecidas na Constituição Federal (Martins e Molinaro, 2013).

No setor saúde, apesar do discurso que defende o SUS, as medidas reformistas também caminham no sentido de modernizar e racionalizar a condução do processo de implantação desse sistema. No campo da gestão, o governo adota a administração gerencial e instrumentos de informatização para a avaliação e o controle de resultados, ao mesmo tempo em que, na área da assistência, implanta programas restritivos e de baixo custo para as populações mais pobres e fortalece a expansão do setor privado na prestação de assistência ao restante da população (Rizzotto, 2012).

O Programa de Agentes Comunitários de Saúde (Pacs) e o Programa de Saúde da Família (PSF), criados em 1992 e 1994 respectivamente, expressam a contradição da política de saúde nesse período. Por um lado, representam propostas que buscam romper com o modelo médico hegemônico vigente, sugerindo a reconfiguração da atenção à saúde no país (Albuquerque, 2003; Vieira et al., 2011). Por outro, são interpretados como políticas restritivas do governo, direcionadas às populações em situação de extrema pobreza (Vieira et al., 2011; Rizzotto, 2012), “em resposta à intensificação das políticas neoliberais a partir da década de 1990" (Vieira et al., 2011, p. 23).

Da mesma forma contraditória é interpretada a incorporação e o aumento substantivo do número de agentes comunitários de saúde (ACSs) no SUS (Vieira et al., 2011). Apesar de serem considerados profissionais importantes para a mudança no modelo de atenção, esses trabalhadores estão submetidos a precárias condições de trabalho, expressas na baixa remuneração, na falta de acesso a uma formação técnica adequada, no desvio de suas funções e na sua vinculação institucional (Queirós e Lima, 2012; Morosini, 2010; Oliveira Júnior, 2012).

Desde a criação da profissão, essa categoria profissional reivindica a regulamentação do seu trabalho, tendo conquistado, nos anos 2000, alguns avanços relativos a seu vínculo, formação profissional e remuneração. Todavia, essas conquistas aconteceram concomitantemente à disseminação de novas formas menos reguladas de vinculação dos trabalhadores e de novos modelos organizacionais de gestão dos serviços de saúde. Foi expressivo o aumento do número de contratos precários e informais durante o governo de FHC, e o PSF se constituiu no exemplo emblemático da utiliza- 
ção das novas formas contratuais ou novos modelos flexíveis de gestão do trabalho (Teixeira, Oliveira e Arantes, 2012; Martins e Molinaro, 2013).

A contratualização dos cuidados primários de saúde é uma tendência internacional das reformas dos sistemas de saúde, adotada na década de 1990 e 2000, em especial, nos países da Europa Ocidental (Escoval, 2010). No Brasil, esse mecanismo de gestão foi adotado na atenção básica e se deu entre as três esferas governamentais por meio do Programa de Melhoria de Acesso e Qualidade (Brasil, 2012), com base em parcerias estabelecidas entre a administração direta e instituições do terceiro setor. É o caso do modelo contratual realizado entre a Fundação Estatal de Saúde da Família (Fesf) e as gestões municipais do estado da Bahia e daquelas parcerias firmadas entre OSs e a administração pública municipal de São Paulo (Carneiro Júnior, Nascimento e Costa, 2011) e do Rio de Janeiro (Magnago, 2012).

Malik (2010) chama a atenção para a necessidade de a contratualização dos serviços de saúde considerar três aspectos: a assistência, a gestão e a comunidade. Para a autora, esses pontos precisam ser olhados de forma sistêmica, de modo que a pactuação das metas e indicadores faça sentido e defina as necessidades de saúde da população a ser atendida.

Neste estudo, esse esforço foi realizado com base na análise da adoção do modelo de gestão por OSs no município do Rio de Janeiro, enfatizando suas repercussões na gestão do trabalho do ACS e no modelo de atenção à saúde implantado na Atenção Básica à Saúde (ABS), tendo em vista a expansão da cobertura assistencial da Estratégia Saúde da Família (ESF) no período 2009 a 2012. Parte-se do entendimento de que a contratação das OSs, além de flexibilizar as relações de trabalho dos profissionais da ESF, induz, mediante a contratualização, uma lógica privada de funcionamento e organização do trabalho que repercute no modelo de gestão do trabalho e no modelo de atenção à saúde prestado à população.

\section{Estudo de caso e pesquisa de campo}

Os dados que serviram de base para a análise proposta fazem parte de um estudo de caso exploratório ${ }^{3}$ de corte transversal e abordagem qualitativa, realizado no período de agosto de 2012 a janeiro de 2013, no município do Rio de Janeiro. A pesquisa de campo desenvolveu-se em três etapas: levantamento de documentos; 4 entrevistas semiestruturadas; e grupos focais. $\mathrm{O}$ levantamento documental foi realizado no período de agosto a novembro de 2012 e visou compreender como foi organizado o processo de expansão da ESF e o processo de contratualização com as OSs.

As entrevistas foram feitas no período de setembro de 2012 a janeiro de 2013. Participaram cinco entrevistados gestores de diferentes níveis de 
gestão, um entrevistado representante do movimento organizado dos trabalhadores e dois entrevistados representantes da Escola Técnica Izabel dos Santos. Buscou-se privilegiar sujeitos sociais com diferentes experiências em relação ao objeto da pesquisa, de forma a compor um grupo diversificado de atores envolvidos, o que permitiu captar semelhanças e diferenças de suas opiniões (Gatti, 2005) acerca do modelo de gestão e de atenção implantados.

Por último, realizaram-se dois grupos focais, cuja composição teve como critério o tempo de inserção dos trabalhadores no sistema de saúde local, com o intuito de compreender se há diferenças no entendimento desses trabalhadores sobre as diretrizes políticas que conformam o seu trabalho. Dessa forma, participaram do grupo focal 1 sete ACSs que foram incorporados à ESF no período de 2009 a 2012. No grupo 2, participaram sete ACSs com mais de cinco anos de experiência de trabalho na assistência básica.

Após a coleta de dados, foi feita a transcrição do conteúdo coletado, seguida da leitura de cada documento produzido. Para auxiliar o processo, a organização e a interpretação dos dados, utilizaram-se categorias eleitas antes da ida ao campo e outras que emergiram durante o percurso da pesquisa, quais sejam: expansão da atenção básica; modelo de gestão; contratualização; vinculação institucional; formação do ACS; remuneração do ACS; natureza do trabalho do ACS; e perfil profissional do ACS.

A análise dos dados coletados foi realizada a partir de um percurso dialético que, segundo Minayo (2008), funda-se na possibilidade de interpretar, de estabelecer relações e de extrair conclusões em todas as direções dos textos, bibliografia, narrativa, entrevista, documento, livro, artigo, dentre outros. Para a autora, a perspectiva dialética estabelece uma atitude crítica, que não se limita apenas a compreender e interpretar; considera também as relações sociais historicamente dinâmicas, antagônicas e contraditórias entre classes, grupos e culturas (Minayo, 2008).

A interpretação dos dados foi realizada de forma a compreender o contexto em que se insere o trabalho do ACS. Num primeiro momento, deu-se a partir da contextualização sócio-histórica dos modelos flexíveis de gestão implantados no setor público em nível nacional, que constituiu um marco teórico fundamental para esta análise. Num segundo momento, ocorreu mediante o retorno ao fato empírico, de forma a compreender a significação particular do caso estudado e a sua articulação com o todo histórico (Minayo, 2008).

O projeto de pesquisa foi submetido e aprovado pelos comitês de ética e pesquisa da Escola Nacional de Saúde Pública Sergio Arouca, da Fundação Oswaldo Cruz (Ensp/Fiocruz) e da Secretaria Municipal de Saúde e Defesa Civil do Rio de Janeiro (SMSDC-RJ) nos meses de julho e setembro de 2012, respectivamente. A aprovação na SMSDC-RJ foi pré-requisito para o desenvolvimento do trabalho em campo. 


\section{O modelo de gestão do trabalho da ESF e o trabalho do ACS no município do Rio de Janeiro}

Historicamente, o sistema municipal de saúde do Rio de Janeiro caracterizou-se pela centralidade na atenção hospitalar e em especialidades médicas. Essa configuração está relacionada ao fato de o município ter sido capital federal até 1960, e, consequentemente, ter herdado uma ampla rede de serviços hospitalares, mas com oferta deficitária de serviços básicos de saúde, além dos entraves políticos e institucionais decorrentes da fusão entre o estado da Guanabara, antiga capital, e o estado do Rio de Janeiro (Parada, 2001; Cazelli, 2003).

De acordo com a literatura consultada, o processo de expansão da ABS localmente se deu pela primeira vez, de maneira mais significativa, no período 2003-2005, de forma complementar à rede de atenção básica em saúde existente. Isso proporcionou a composição de um 'mosaico' de diferentes unidades e prestação de serviços nesse nível de atenção (Parada, 2001; Cazelli, 2003). Nesse período, a vinculação dos profissionais da ABS era realizada por intermédio da administração direta ou por meio de organizações não governamentais (ONGs), associações de moradores e cooperativas (Parada, 2001; Magnago, 2012).

A partir de 2009, a expansão da Atenção Primária à Saúde (APS) 5 entrou na agenda da gestão municipal, e foram realizadas diversas mudanças na rede de atenção e na estrutura da gestão local. O grupo político que assumiu a SMSDC-RJ em 2009 havia se comprometido na campanha eleitoral com a reformulação do sistema de saúde local e, segundo um dos entrevistados, estruturou "um novo plano de saúde para a cidade (...) com algumas estruturas e atributos importantes para a sua condução" (Subsecretário de Atenção Primária, Promoção e Vigilância em Saúde). Um dos objetivos desse novo plano era fortalecer o sistema de saúde local, tomando como exemplo os sistemas de saúde das cidades olímpicas e o sistema de saúde de Portugal, cuja base é a APS.

Apesar dessa intenção, o grupo político eleito partiu da realidade sanitária e estrutural local e seguiu as diretrizes da Política Nacional de Atenção Básica à Saúde (Brasil, 2012). Dessa forma, optou-se pela ESF como proposta de reorientação do modelo de atenção em saúde, com sua cobertura aumentando de 9,24\% para 39,84\% de 2009 a 2012 (Brasil, 2013).

A fim de operacionalizar, executar e apoiar as ações e serviços de saúde da família, a SMSDC-RJ optou pela contratação de OSs, seguindo as diretrizes e argumentos do Plano Diretor da Reforma do Aparelho do Estado (Brasil, 1995). Segundo os gestores entrevistados, foram justificativas para a adoção das OSs a burocracia e a morosidade do setor público em contratar e demitir profissionais; a necessidade de competição dos salários dos profissionais 
médicos com o setor privado; e as vantagens desse modelo de gestão em relação às formas de contratações anteriores (ONGs, cooperativas, associação de moradores).

A implantação das organizações sociais para a gestão dos serviços da ESF no município do Rio de Janeiro foi realizada mediante negociação com a Câmara dos Vereadores em 2009. Após duas audiências públicas realizadas pelas comissões de Saúde e de Educação da Câmara de Vereadores, foi aprovado, no dia 27 de abril de 2009, o projeto de lei n. 02/2009, de autoria do então prefeito da cidade, que dispôs sobre a qualificação de entidades como as OSs. Houve resistências de conselhos profissionais, movimentos organizados de trabalhadores e entidades como o Conselho Municipal de Saúde à implantação do projeto de lei do Executivo. No entanto, em maio de 2009, a qualificação das OSs ocorreu por meio da lei n. 5.026/2009 e de sua regulamentação posterior pelo decreto n. 30.780/09.

Em agosto de 2009, a SMSDC-RJ tornou pública a sua intenção de criar parceria com OSs, publicando no Diário Oficial do município editais de seleção pública para entidades privadas sem fins lucrativos, nos quais se especificavam as unidades a serem gerenciadas pela administração indireta e definiam a área de atuação de cada OS. No momento de realização da pesquisa, existiam cinco OSs atuando no âmbito do gerenciamento da ESF no município do Rio de Janeiro que assinaram contrato de gestão com a SMSDC-RJ.

Para que as OSs cumpram com o objeto contratado, a SMSDC-RJ repassa recursos orçamentários com um valor fixo e um valor variável, de acordo com o cronograma financeiro definido no anexo dos contratos de gestão. A parte fixa consiste em repasse trimestral antecipado, destinado ao custeio de recursos humanos e da prestação de serviços de manutenção, funcionamento e restaurações das unidades, enquanto a parte variável corresponde ao montante pago, também trimestralmente, com base na apresentação e avaliação de relatórios de produtividade e qualidade dos serviços prestados de acordo com indicadores e metas preestabelecidos.

O novo desenho de gestão da ABS significou uma mudança no papel da administração direta na condução da política de saúde, na organização dos serviços e ações de saúde da família e na gestão do trabalho dos profissionais da ESF. As OSs ficaram responsáveis pela execução da política, contratação e pagamento dos profissionais, ao passo que a administração direta assumiu as funções relativas ao financiamento, indução e regulação.

No que tange à gestão do trabalho em saúde, a administração direta transferiu para as OSs a responsabilidade de contratar e estabelecer normas de seleção, demissão e remuneração para os profissionais das equipes, além de introduzir o mecanismo de contratualização nos serviços de saúde da família, suscitando mudanças na forma de organizar e avaliar o processo de trabalho das equipes e dos profissionais. 
Para Martins e Molinaro (2013), nos novos modelos de gestão flexíveis, os trabalhadores e o trabalho são avaliados e monitorados com base no cumprimento de metas preestabelecidas, sem que haja normas reguladoras de desempenho, admissão e demissão - o que fragiliza a vinculação dos profissionais com os serviços públicos e a continuidade da política de saúde.

Os efeitos dessas formas de vinculação se diferenciam conforme a qualificação profissional dos trabalhadores das equipes da ESF, dando especial ênfase ao caso dos ACSs. A pauta sobre a vinculação institucional desses trabalhadores esteve associada, durante muitos anos, a uma leitura acrítica e naturalizada acerca de seu perfil social (Morosini, 2010). A principal questão em debate está relacionada ao fato de o ACS ser morador da comunidade, o que dificulta a sua admissão no serviço público por meio de concurso público, visto que isso contraria o princípio do acesso igualitário e universalista aos cargos públicos (Brasil, 2002).

Mesmo com essa alegação, normativamente houve mudanças significativas tanto na dimensão jurídica da relação do trabalho do ACS quanto na dimensão administrativa da relação institucional desse trabalhador com a administração direta. Três atores foram de fundamental importância nesse processo: a Confederação Nacional dos Agentes Comunitários de Saúde, o Ministério Público do Trabalho e a Secretaria da Gestão do Trabalho e da Educação na Saúde (Morosini, 2010).

O resultado dessa disputa foi a promulgação da emenda constitucional n. 51, de 14 de fevereiro de 2006, e da lei n. 11.350/2006, que buscaram reverter a situação de ilegalidade dos vínculos e da admissão dos ACSs nos serviços públicos. Os documentos previram a admissão de ACSs e agentes de endemias mediante processo seletivo público (Brasil, 2006a), estabelecendo que os ACSs deveriam ser admitidos pelos gestores locais do SUS, submetendo-se ao regime jurídico estabelecido pela CLT, e não poderiam ter sua contratação terceirizada ou temporária, salvo em hipóteses de combate a surtos endêmicos (Brasil, 2006b).

No município do Rio de Janeiro, o vínculo dos ACSs durante muitos anos se deu por meio de parcerias da administração direta com ONGs e associações de moradores. A partir de 2009, sua vinculação institucional passou a ser estabelecida por meio das OSs e regida pela CLT, apesar das tentativas de negociação do movimento organizado com a Prefeitura acerca dessa questão no momento de transição do governo. A contratação via OSs foi imposta pela SMSDC-RJ, sob a alegação de que essa forma de vínculo seria melhor quando comparado às anteriormente estabelecidas na ESF.

Para o Sindicato dos Agentes Comunitários de Saúde do Rio de Janeiro (Sindacs-RJ), apesar de garantir os direitos trabalhistas, a contratação por meio de OSs não é a melhor forma de vinculação a ser estabelecida com a categoria, tendo em vista a instabilidade e a insegurança que esse vínculo tem ocasionado. 
O vínculo aqui é indireto e precário. Eu considero precário, mesmo você tendo seus direitos trabalhistas garantidos. Muitos superiores, gestores, gerentes, o pessoal da OS usa isso para assédio moral (Representante do Sindacs-RJ).

O tempo de vigência do contrato das OSs com a SMSDC-RJ é de dois anos, podendo ser renovado uma vez, pelo mesmo período, caso haja interesse da SMSDC-RJ, e outra vez, por um ano, se atingidas as metas pactuadas no contrato de gestão. Além disso, existe a possibilidade de rescisão contratual entre as partes (Rio de Janeiro, 2011), que, quando ocorreram, comprometeram os direitos trabalhistas dos profissionais.

Já são umas duas ou três OSs que saíram, que sumiram e deixaram as pessoas sem salário. O pessoal ficou sem fundo de garantia. (...) Até hoje tem muita gente que não recebeu. Está na Justiça (Representante do Sindacs-RJ).

Essa conjuntura de instabilidade e precarização da vinculação institucional dos ACSs tem suscitado o debate entre o sindicato e a SMSDC-RJ quanto à possibilidade de efetivação desses profissionais no município. Além disso, traz à tona a discussão acerca da autonomia e qualificação desse trabalhador.

\section{A contratualização dos serviços de saúde da família, o processo de trabalho do ACS e as repercussões no modelo de atenção à saúde}

A contratualização está no centro das discussões sobre alternativas para a administração pública do setor saúde no país, tendo em vista a melhoria do desempenho e da prestação de contas dos prestadores de serviços (Lima e Rivera, 2012). Esse mecanismo de gestão segue a lógica da nova gestão pública e do modelo gerencialista do Estado, que "têm como pressupostos a superioridade prática da gestão privada, pelo que o caminho da intervenção pública deve ser a aproximação constante às práticas da gestão empresarial" (Antunes et al., 2011, p. 192).

Para alguns autores, os arranjos contratuais, mundialmente adotados nas reformas do setor saúde, apresentam-se como formas de induzir um método mais eficaz de desempenho e maior accountability, com base na definição de um conjunto de serviços vinculados a um orçamento (Costa, Ribeiro e Silva, 2000). Em contrapartida, tem-se argumentado que a contratualização introduz nos serviços públicos, especificamente no setor saúde, uma lógica de organização e funcionamento do setor privado (Paula, 
2005) pautada em valores de produtividade, competitividade e desempenho (Rizzotto, 2012), podendo comprometer a gestão do trabalho em saúde e o modelo de atenção à saúde prestado à população (Malik, 2010).

No Brasil, os arranjos contratuais têm sido realizados entre o núcleo central da administração pública e os entes federativos estaduais e municipais, ou com prestadores de serviços inscritos nas novas modalidades jurídico-administrativas público ou privadas, como as OSs e as fundações estatais (Lima e Rivera, 2012).

A gestão municipal de saúde do Rio de Janeiro adotou, em 2009, o mecanismo de contratualização para o gerenciamento dos serviços de saúde da família a partir de parceria firmada com OS, que teve como objetivo

(...) induzir e melhorar o desempenho das unidades funcionais, através da atribuição de incentivos financeiros e da criação de instrumentos de monitorização, permitindo uma gestão rigorosa e equilibrada, consciente das necessidades das populações e, acima de tudo, visando a melhoria no acesso aos cuidados de saúde para se poder alcançar maiores ganhos em saúde (Rio de Janeiro, 2011, p. 99).

O contrato de gestão foi o instrumento utilizado para firmar a parceria entre as OSs e a administração pública, e foi por meio dele que o Estado transferiu recursos para as OSs executarem os serviços anteriormente prestados por ele. Nesse documento, definiram-se os serviços de saúde a serem oferecidos pela contratada; sugeriu-se uma carteira básica de serviços, na qual consta a produção mínima de procedimentos esperados para cada profissional; descreveram-se os mecanismos e critérios de avaliação e acompanhamento dos serviços prestados pela OS, além dos indicadores de acompanhamento, avaliação e metas atrelados ao pagamento da parte variável do recurso financeiro, repassada de acordo com os resultados do desempenho alcançados pelas instituições, unidades de saúde e equipes (Rio de Janeiro, 2011).

O levantamento dos dados identificou que os ACSs têm utilizado a carteira básica de serviços e a matriz de indicadores, esta última proposta nos contratos de gestão para a organização do seu processo de trabalho. A carteira de serviços sugere uma semana-padrão dividida em dez turnos semanais, especificando as ações e o número mínimo de procedimentos esperados no período de uma semana (Quadro 1). 
Quadro 1

\begin{tabular}{|c|c|c|c|c|}
\hline Ações & $\begin{array}{l}\text { N. de turnos na } \\
\text { semana } \\
\text { (A) }\end{array}$ & $\begin{array}{l}\text { N. de ações } \\
\text { por turno } \\
\text { (B) }\end{array}$ & $\begin{array}{l}\text { N. de ações por } \\
\text { semana } \\
(C)=\left(A^{*} B\right)\end{array}$ & $\begin{array}{c}\text { Meta mínima de } \\
\text { acompanhamento } \\
D=\left(C^{*} 4\right)\end{array}$ \\
\hline Visita domiciliar de acompanhamento & 6 & 6 & 36 & 144 \\
\hline Acolhimento e humanização na unidade & 2 & - & - & - \\
\hline Busca ativa e vigilância em saúde & 1 & - & - & Não se aplica \\
\hline Reunião de equipe & 1 & - & - & Não se aplica \\
\hline
\end{tabular}

Fonte: Os autores.

Observou-se que na semana-padrão proposta para os ACSs pela SMSDC-RJ falta a inclusão de atividades de grupos/encontros com a comunidade, com ênfase na promoção da saúde e prevenção das doenças (Oliveira Júnior, 2012). O trabalho desse profissional está focado nas visitas domiciliares, no acolhimento dentro da unidade e em ações administrativas relativas à entrega de medicamentos, marcação de consultas, alimentação dos sistemas de informação etc.

Ao estudar a institucionalização do trabalho do ACS, Queirós e Lima (2012) compreenderam que a ordem dominante tem modificado o trabalho desse profissional e, quando não altera a sua prática, "tenta modificá-la através dos desvios de função, como marcação de consulta, recepção, entre outras atividades" (Queirós e Lima, 2012, p. 277). Para as autoras, apesar da forte investida institucional na centralidade da prática do ACS, há uma resistência da categoria e de seus apoiadores na defesa das funções de mobilizador e educador como papéis essenciais desses profissionais e na continuação da luta por um projeto popular para a saúde, como pode ser visto nas falas seguintes:

A gente está trabalhando com algumas coisas que eu acho que não é trabalho de agente de saúde. Por exemplo, (...) verificar pressão. Que eu saiba, o agente de saúde não é para verificar a pressão. Não é técnico (ACS, grupo focal 1).

Eu acho que o papel do ACS é o de um agente de promoção, de transformação. É buscar melhoria para onde ele mora, melhoria para onde ele trabalha. É ser uma pessoa crítica, (...) que faz as pessoas refletirem sobre aquela situação que está acontecendo (Representante do Sindacs-RJ). 
Com base nesse entendimento trazido pelos trabalhadores acerca de sua prática profissional, observou-se a recorrência de críticas às atividades sugeridas na semana-padrão, no sentido de que ela tem ocasionado 'desvio' de suas funções no cotidiano de trabalho:

Eles deviam tirar a gente do acolhimento, da recepção. (...) Ali não é o nosso lugar, o nosso é lugar é na comunidade (...). Esse vínculo que a gente tem é lá na comunidade. A gente tem que subir o morro mesmo, não tem que ficar aqui embaixo não (ACS, grupo focal 2).

Porque antigamente a gente fazia palestras, a gente fazia reuniões. Hoje em dia só faz visita domiciliar e acolhimento, e nada mais (ACS, grupo focal 2).

Oliveira Júnior (2012), ao estudar o processo de trabalho dos ACSs no município do Rio de Janeiro, demonstrou que existe uma tensão nas equipes para o alcance das metas de produtividade propostas na semana-padrão e que, para os ACSs, essa pressão está mais voltada para o cumprimento das metas das visitas domiciliares.

Na presente pesquisa, a maioria dos participantes relatou a relação entre a lógica de produtividade e o tempo disponível para realizar suas ações e como isso influencia na sua forma de atuação junto da população.

Nós temos que trabalhar muito mais rápido do que antes. (...) Antes nós parávamos, escutávamos. Quando ultrapassava o limite, aí nós conversávamos com aquela pessoa da melhor maneira, para voltar outro dia, e a pessoa ficava bem. (...) Eu não vou deixar a pessoa chorando e dizer: "Tchau, eu vou ter que ir embora, porque eu tenho doze visitas hoje" (ACS, grupo focal 2).

Hoje você tem que falar "oi, tudo bem?", anotar tudo e sair correndo (ACS grupo focal 2).

Esses achados corroboram o estudo de Oliveira Júnior, para quem

a valorização da quantidade de visitas (...) torna essa prática de contatos com a população cada vez mais breve, de caráter prescritivo e de vigilância, abreviando os diálogos pela falta de tempo e anulando os espaços de escuta e acolhimento (Oliveira Júnior, 2012, p. 99).

Há, portanto, uma relação entre a assistência, a comunidade e a gestão durante o processo de contratualização que deve ser considerada de forma sistêmica a fim de que se atendam as necessidades de saúde da população (Malik, 2010). 
De acordo com as falas dos participantes dos grupos focais, cada vez mais parece que o seu trabalho é definido pela lógica da produtividade e do alcance das metas pactuadas, afastando-se das necessidades de saúde da população.

Hoje em dia eles não estão preocupados com os pacientes com as causas dos problemas dos pacientes. Eles estão preocupados com a quantidade do sistema (ACS, grupo focal 2).

Além da semana-padrão sugerida, os contratos de gestão estabeleceram os indicadores de desempenho a serem implantados pelas OSs e avaliados pela SMSDC-RJ. Durante o período estudado, houve significativa mudança nos indicadores pactuados e na lógica de repasse financeiro correspondente ao alcance de suas metas. Num primeiro momento, os indicadores foram organizados por eixos norteadores, relativos ao plano de trabalho das equipes e às linhas de cuidados prioritárias da SMSDC-RJ, e o repasse orçamentário realizado em um montante único.

A partir de 2010, adotou-se o modelo de programa de pagamento por desempenho (pay-for-performance - $\mathrm{P} 4 \mathrm{P}$, ou value based purchasing), baseado na experiência do sistema de saúde português, que introduziu três variáveis para o repasse do recurso financeiro: parte variável 1: conjunto de indicadores para incentivo institucional à gestão do território integrado de atenção à saúde (Teias); parte variável 2: composta por quatro grupos de indicadores - acesso, desempenho assistencial, satisfação do paciente, eficiência - que devem ser cumpridos para o incentivo institucional à unidade de saúde; e parte variável 3: incentivo à equipe de saúde da família e saúde bucal para complemento de salário dos profissionais (Rio de Janeiro, 2011).

De acordo com Teixeira (1999), o pagamento por desempenho é uma das estratégias de flexibilização da nova dinâmica de incorporação e gestão do trabalho presente tanto no setor público quanto no setor privado. Consiste na remuneração composta pela combinação de salários fixos com uma participação em resultados alcançados que leva em conta a performance individual do trabalhador.

Uma análise dos indicadores pactuados e do incentivo financeiro correspondente mostrou que há conversão de uma parcela do recurso que deveria ser investido em questões estratégicas de melhoria da qualidade dos serviços, como a adaptação das unidades, a formação dos profissionais e o aumento salarial, em componente flexível de pagamento. Esse fato pode ser agravado pela inexistência de regulação externa dos contratos de gestão, que sugere que a distribuição e a realocação de recursos ficam dependentes das variações orçamentárias e políticas das parcerias estabelecidas entre a administração direta e as OSs. Consequentemente, diz respeito à qualidade 
da política de saúde prestada e à responsabilidade da administração pública pela profissionalização dos trabalhadores da ESF.

Observou-se que, na contratualização realizada no município do Rio de Janeiro, o pagamento por desempenho recai sobre a 'premiação' por produtividade e tem contribuído para a competitividade entre unidades, equipes e profissionais, como pode ser visto na fala a seguir:

Tem uma competição por causa dos indicadores. Eles [referindo-se aos ACS 'novos'] querem colocar no sistema: fez dez visitas hoje, eu vou lançar no sistema, porque eu quero que minha equipe bata meta. (...) Eu penso em dar um atendimento de qualidade. Não é chegar aqui e mostrar o número porque ele pediu número, só para poder bater meta (ACS, grupo focal 2).

Matos et al. (2010) atentam para o fato de que o alcance de bons resultados dos arranjos contratuais depende tanto da coordenação desse processo quanto da motivação dos profissionais que participam da prestação dos serviços de saúde. Para os autores, isso implica necessariamente um processo de contratualização interna, envolvendo a participação dos atores com a prestação de serviços durante todas as fases da contratualização.

Na contratualização realizada para os serviços da ESF no município do Rio de Janeiro, percebeu-se a inexistência de participação dos trabalhadores e de controle social nas etapas de negociação, construção de instrumento e gerenciamento. No período estudado, houve uma centralização das definições na gestão central da SMSDC-RJ que repercutiu no distanciamento entre os indicadores pactuados, as necessidades de saúde da população e a realidade de trabalho dos profissionais nas unidades, como pode ser visto na fala do gerente de unidade entrevistado:

A gente até vem funcionando, mas existem também alguns indicadores que não estão adequados ao nosso processo de trabalho. Precisa rever essa meta, até para saber se precisa readequar o processo de trabalho. Então não existe essa discussão (Gerente de unidade).

Esses achados estão em consonância com aqueles encontrados no relatório final da pesquisa realizada por Escoval et al. (2010) acerca do processo de contratualização dos cuidados primários de saúde em Portugal. Segundo esse texto, apesar dos avanços alcançados pelos novos modelos de contratualização no setor saúde no país, é necessário aprimorar os indicadores, no sentido de aproximá-los da realidade de saúde da população e de trabalho dos profissionais.

Destaca-se que a não participação dos trabalhadores nos momentos de negociação, monitoramento e avaliação dos indicadores e metas reproduz 
um modelo de gestão do trabalho verticalizado no qual ocorre a separação entre a formulação e a execução das atividades, além da tendência a reproduzir um modelo de atenção centrado na produtividade e no alcance de metas que pode não resultar em ganhos de saúde para a população.

\section{Considerações finais}

Pensar os novos modelos de gestão do trabalho no SUS implica refletir sobre as conquistas sociais dos trabalhadores e o modelo de atenção sugeridos pela Constituição Federal de 1988. Para isso é de fundamental importância colocar, além das necessidades de saúde da população, o trabalho e o trabalhador no centro das investigações acerca das relações público-privadas estabelecidas mais recentemente na administração pública, pois isso implica considerá-los fundamentais para o processo de consolidação do SUS.

A pesquisa revelou que as novas modalidades de gestão do trabalho introduzidas na administração pública pela reforma do Estado adotam estratégias, valores e ações próprias do setor privado, desresponsabilizando o Estado no provimento das políticas públicas e flexibilizando as relações de trabalho estabelecidas em lei. Isso trouxe repercussões para os trabalhadores no que tange a segurança, autonomia, função, remuneração, tempo e gestão 'no' e 'do' seu trabalho.

Para os ACSs, especificamente, viu-se que a introdução do mecanismo de contratualização nos serviços da ESF no município do Rio de Janeiro induziu a construção de um saber institucional que altera a prática cotidiana e o sentido do trabalho desses profissionais, além de favorecer a competição e a produtividade. Essa lógica de organização do mundo do trabalho repercutiu na produção do cuidado e no atendimento das necessidades de saúde da população.

Desta forma, compreende-se que os modelos de gestão do trabalho adotados no setor público da saúde devem pautar-se numa concepção de resultados e metas que envolva as demandas e necessidades de saúde da população, as condições de trabalho e de produção dos profissionais, além do acesso e incorporação de novas tecnologias materiais e imateriais de produção.

No âmbito das relações de trabalho, viu-se que a trajetória das políticas de gestão do trabalho adotadas no setor público de saúde a partir da institucionalização do RJU levaram a uma fragilização desse tipo de regime de contratação e à incorporação de novos atores sociais na administração pública, entre eles as cooperativas, as OSs e as fundações estatais de direito privado. Isso tem oportunizado a temporalidade e a externalidade dos vínculos de trabalho dos profissionais do SUS com o Estado, tornando-se necessária a retomada da discussão de modelos contratuais mais estáveis e 
menos precários, como aquele sugerido na Constituição Federal e na proposta de emprego público.

\section{Colaboradores}

Carla Cabral Gomes Carneiro redigiu o texto e Maria Inês Carsalade Martins participou da elaboração como orientadora.

Resumen Este artículo discute la asociación del Estado con organizaciones sociales para la gestión del trabajo en salud en el sector público, con énfasis en el trabajo del agente comunitario de salud. Se trata de un estudio de caso realizado en el municipio de Río de Janeiro, Brasil, en una coyuntura de expansión de la cobertura de la Estrategia Salud Familiar. El tema se analiza en un contexto más amplio de reforma del Estado brasileño, partiendo de la base de que el movimiento reformista de la administración pública, conocido como gerencialismo, guarda estrecha relación en sus acciones y valores con la restructuración productiva iniciada en los años 70. Los resultados muestran que el modelo de gestión del trabajo implantado opera bajo la lógica de la productividad, influyendo sobre el modelo de atención de la salud prestado a la población y la organización del trabajo del agente comunitario de salud. El análisis también destaca la temporalidad y la externalidad de los vínculos de trabajo como factores que pueden comprometer los avances de la democratización, equidad y ciudadanía en el campo de la salud y del trabajo conquistados en la Constitución brasileña de 1988.

Palabras clave nuevos modelos de gestión del trabajo en salud; reforma del Estado; contractualización; trabajo en salud; agente comunitario de salud. 


\section{Notas}

1 Fundação Oswaldo Cruz, Manguinhos, Rio de Janeiro, Brasil.

Mestre em Saúde Pública pela Escola Nacional de Saúde Pública Sergio Arouca, Fundação Oswaldo Cruz.

<carlacgc@yahoo.com.br>

Correspondência: Fundação Oswaldo Cruz, Escola Nacional de Saúde Pública Sergio Arouca, Departamento de Ciências Sociais, sala 924, Rua Leopoldo Bulhões, 1.480, Manguinhos, CEP 21041-210, Rio de Janeiro, RJ, Brasil.

2 Fundação Oswaldo Cruz, Manguinhos, Rio de Janeiro, Brasil.

Doutora em Saúde Coletiva pela Universidade do Estado do Rio de Janeiro

$<$ mines@fiocruz.br $>$

3 Este artigo resultou da dissertação de mestrado em Saúde Pública $O$ trabalho do agente comunitário e suas determinações: um estudo de caso do município do Rio de Janeiro, de autoria de Carla Cabral Gomes Carneiro, realizado na Ensp/Fiocruz, com financiamento da Coordenação de Aperfeiçoamento de Pessoal de Nível Superior (Capes) por meio de bolsa de mestrado.

4 O levantamento documental contemplou os seguintes documentos: lei municipal n. 5.026/09; decreto municipal n. 30.780/09; contratos de gestão firmados entre as OSs e a SMSDC-RJ de 2009 a 2012; editais de seleção pública para ACS disponíveis em meio digital; carteira de serviços de atenção primária; cartilha de orientações para expansão das clínicas da família no município do Rio de Janeiro; plano municipal de saúde do município do Rio de Janeiro.

5 Optou-se pela adoção da nomenclatura 'APS' (Atenção Primária à Saúde), pelo fato de que a gestão municipal de saúde do Rio de Janeiro, diferentemente da política nacional de atenção básica, adotou esta denominação.

\section{Referências}

ALBUQUERQUE, Paulette C. A educação popular em saúde no município de Recife-PE: em busca da integralidade. 2003. 193f. Tese (Doutorado em Saúde Pública) - Centro de Pesquisas Aggeu Magalhães, Escola Nacional de Saúde Pública, Fundação Oswaldo Cruz, Recife, 2003.

ANTUNES, Edite et al. Contratualização em saúde: efectividade do sistema de incentivos. In: CONGRESSO NACIONAL DA ADMINISTRAÇÃO PÚBLICA, 8. Anais... Lisboa:
Instituto Nacional de Administração, 21 e 22 de novembro de 2011. p. 191-217. Disponível em: <http://repap.ina.pt/bitstream/ 10782/582/1/Contratualizacao $\% 20$ em $\% 20$ saude $\% 20 \_\% 20$ efectividade.pdf $>$. Acesso em: 9 abr. 2014.

ANTUNES, Ricardo. A nova morfologia do trabalho: suas principais metamorfoses e balanço preliminar. In: GUIMARÃES, Cátia (Org.). Trabalho, Educação e Saúde: 25 anos de formação politécnica no SUS. Rio de 
Janeiro: Escola Politécnica de Saúde Joaquim Venâncio, 2010. p. 11-28.

BRASIL. Ministério da Administração Federal e da Reforma do Estado. Plano Diretor da Reforma do Aparelho do Estado. Brasília: Imprensa Nacional, 1995.

BRASIL. Ministério da Saúde. Secretaria de Políticas de Saúde. Departamento de Atenção Básica. Modalidade de contratação de agentes comunitários de saúde: um pacto tripartite. 1. ed., 1. reimpr. Brasília: Ministério da Saúde, 2002. (Série C: Projetos, programas e relatórios).

BRASIL. Emenda constitucional n. 51, de 14 de fevereiro de 2006. Acrescenta os $\$ \S 4^{\circ}$, $5^{\circ}$ e $6^{\circ}$ ao art. 198 da Constituição Federal. Diário Oficial da União, Brasília, seção 1, p. 1, 15 fev. 2006 a.

BRASIL. Lei n. 11.350, de 5 de outubro de 2006. Regulamenta o $\S 5^{\circ}$ do art. 198 da Constituição, dispõe sobre o aproveitamento de pessoal amparado pelo parágrafo único do art. $2^{\circ}$ da emenda constitucional n. 51, de 14 de fevereiro de 2006, e dá outras providências. Diário Oficial da União, Brasília, seção 1, p. 1, 6 out. 2006 b.

BRASIL. Ministério da Saúde. Politica Nacional de Atenção Básica. Brasília: Ministério da Saúde, 2012. (Série E: Legislação em saúde).

BRASIL. Ministério da Saúde. Sala de apoio à gestão estratégica. Brasília: Ministério da Saúde, 2013. Disponível em: <http://189. 28.128.178/sage/>. Acesso em: 9 maio 2013.

CARNEIRO JÚNIOR, Nivaldo; NASCIMENTO, Vânia B.; COSTA, Ieda M. C. Relação entre público e privado na atenção primária à saúde: considerações preliminares. Saúde e Sociedade, São Paulo, v. 20, n. 4, p. 971979, 2011.

CAZELLI, Carla M. Avaliação da implementação do Programa Saúde da Família no município do Rio de Janeiro. 2003. 173f. Dissertação (Mestrado em Saúde Pública) - Escola Na- cional de Saúde Pública, Fundação Oswaldo Cruz, Rio de Janeiro, 2003.

COSTA, Nilson R.; RIBEIRO, José M.; SILVA, Pedro L. B. Reforma do Estado e mudança organizacional: um estudo de hospitais públicos. Ciência \& Saúde Coletiva, Rio de Janeiro, v. 5, n. 2, p. 427-442, 2000.

ESCOVAL, Ana et al. Contratualização em cuidados primários em saúde: horizonte 2015/20. Lisboa: Escola Nacional de Saúde Pública/Administração Central de Serviços de Saúde, 2010.

GATTI, Bernadete A. Grupo focal na pesquisa em ciências sociais e humanas. Brasília: Liber, 2005.

LIMA, Júlio C. F. A política nacional de saúde nos anos 1990 e 2000: na contramão da história?. In: PONTE, Carlos F.; FALLEIROS, Ialê (Org.). Na corda bamba de sombrinha: a saúde no fio da história. Rio de Janeiro: Casa de Oswaldo Cruz; Escola Politécnica de Saúde Joaquim Venâncio, 2010. p. 279-310.

LIMA, Sheyla M. L.; RIVERA, Francisco J. U. A contratualização nos hospitais de ensino no Sistema Único de Saúde brasileiro. Ciência \& Saúde Coletiva, Rio de Janeiro, v. 17, n. 9, p. $2.507-2.521,2012$.

MAGNAGO, Carinne. Gestão do trabalho na Estratégia Saúde da Família em municipios do estado do Rio de Janeiro com mais de 500 mil habitantes: o caso do Rio de Janeiro e Duque de Caxias. 2012. 175 f. Dissertação (Mestrado em Medicina Social) - Instituto de Medicina Social, Universidade do Estado do Rio de Janeiro, Rio de Janeiro, 2012.

MALIK, Ana M. Síntese da palestra: Os desafios e as perspectivas do processo de contratualização no contexto brasileiro - 8.12.2008. In: BRASIL. Ministério da Saúde. Análise do processo de contratualização dos hospitais de ensino e filantrópicos no SUS. Brasília: Ministério da Saúde, 2010. (Série D: Reuniões e conferências). p. 15-20. 
MARTINS, Maria I. C.; MOLINARO, Alex. Reestruturação produtiva e seu impacto nas relações de trabalho nos serviços públicos de saúde no Brasil. Ciência \& Saúde Coletiva, Rio de Janeiro, v. 18, n. 6, p. 1.667-1.676, jun. 2013.

MATOS, Tânia T. et al. Contratualização interna vs. contratualização externa. Revista Portuguesa de Saúde Pública, Lisboa, v. 9, p. 161-180, 2010.

MINAYO, Maria C. S. O desafio do conhecimento: pesquisa qualitativa em saúde. 11. ed. São Paulo: Hucitec, 2008.

MOROSINI, Márcia V. Educação e trabalho em disputa no SUS: a política de formação dos agentes comunitários de saúde. Rio de Janeiro: Escola Politécnica de Saúde Joaquim Venâncio, 2010.

OLIVEIRA JÚNIOR, João G. Agentes comunitários de saúde: fatores restritivos e facilitadores do seu trabalho na Estratégia de Saúde da Família. Dissertação (Mestrado em Saúde Pública) - Escola Nacional de Saúde Pública Sergio Arouca, Rio de Janeiro, 2012.

PARADA, Roberto. A construção do sistema estadual de saúde: antecedentes e formas de inserção. Physis: Revista de Saúde Coletiva, Rio de Janeiro, v. 11, n.1, p. 19-114, 2001.

PAUlA, Ana P. P. Administração pública brasileira entre o gerencialismo e a gestão social. Revista de Administração de Empresas, São Paulo, v. 45, n. 1, p. 36-49, jan./mar. 2005.

PAULANI, Leda M. O projeto neoliberal para a sociedade brasileira: sua dinâmica e seus impasses. In: LIMA, Júlio C. F.; NEVES, Lúcia M. W. (Orgs.). Fundamentos da educação escolar do Brasil contemporâneo. Rio de Janeiro: Editora Fiocruz; Escola Politécnica de Saúde Pública, 2006. p. 67-108.

PERDICARIS, Priscilla R. Contratualização de resultados e desempenho no setor público: a experiência do contrato programa nos hospitais públicos da administração direta no estado de São Paulo. 2012. 133f. Tese (Doutorado em Administração Pública e Governo) - Escola de Administração de Empresas de São Paulo, Fundação Getúlio Vargas, São Paulo, 2012.

PEREIRA, Eliane M.; LINHARES, Fernando. O Estado e as políticas sociais no capitalismo. In: MOROSINI, Márcia V. G. C.; REIS, José Roberto F. (Orgs.). Sociedade, Estado e direito à saúde. Rio de Janeiro: Escola Politécnica de Saúde Pública, 2007. p. 63-80.

QUEIRÓS, Agleildes A. L. de; LIMA, Luci P. A institucionalização do trabalho do agente comunitário de saúde. Trabalho, Educação e Saúde, Rio de Janeiro, v. 10, n. 2, p. 257281, out. 2012.

REZENDE, Conceição A. P. O modelo de gestão do SUS e as ameaças do projeto neoliberal. In: BRAVO, Maria I. S. et al. (Org.). Política de saúde na atual conjuntura: modelos de gestão e agenda para a saúde. 2. ed. Rio de Janeiro: Rede Sirius/Adufrj-SSind, 2008. p. 25-35.

RIO DE JANEIRO. Secretaria Municipal de Saúde e Defesa Civil. Minuta do edital de convocação pública para parcerias com organizações sociais, edital e anexos: Estratégia de Saúde da Família AP.1.0. Rio de Janeiro: Subsecretaria de Promoção, Atenção Primária e Vigilância em Saúde - SMSDC-RJ, 2011.

RIZZOTTO, Maria L. F. Capitalismo e saúde no Brasil nos anos 90: as propostas do Banco Mundial e o desmonte do SUS. São Paulo: Hucitec, 2012.

SILVA, Vanice M. As organizações sociais (OS) e as fundações estatais de direito privado (FEDP) no Sistema Único de Saúde: aspectos da relação público-privado e os mecanismos de controle. 2012. 99f. Dissertação (Mestrado em Saúde Pública) - Escola Nacional de Saúde Pública, Fundação Oswaldo Cruz, Rio de Janeiro, 2012.

TEIXEIRA, Márcia. Desenhos alternativos de incorporação e gestão do trabalho médico na SMS do Rio de Janeiro: as experiências dos 
hospitais Lourenço Jorge e Salgado Filho. 139p. Dissertação (Mestrado em Saúde Pública). Fundação Oswaldo Cruz, Escola Nacional de Saúde Pública Sergio Arouca, Rio de Janeiro, 1999.

TEIXEIRA, Márcia; OLIVEIRA, Roberta G. de; ARANTES, Rosana F. Mudanças nas políticas do trabalho e da educação em saúde no Governo Lula. In: MACHADO, Cristiane V.; BAPTISTA, Tatiana W. F.; LIMA, Luciana D. de (Orgs.). Políticas de saúde no Brasil: continuidades e mudanças. Rio de Janeiro: Editora Fiocruz, 2012. p. 197-225.
VIEIRA, Mônica; CHINELLI, Filippina. Relação contemporânea entre trabalho, qualificação e reconhecimento: repercussões sobre os trabalhadores técnicos do SUS. Ciência \& Saúde Coletiva, Rio de Janeiro, v. 18, n. 6, p. 1.591-1.600, jun. 2013.

VIEIRA, Mônica et al. Introdução. In: VIEIRA, Mônica; DURÃo, Ana V.; LOPES, Márcia R. (Org.). Para além da comunidade: trabalho e qualificação dos agentes comunitários de saúde. Rio de Janeiro: Escola Politécnica de Saúde Pública, 2011. p. 23-32.

Recebido em 13/08/2013

Aprovado em 29/09/2013 
